p-ISSN: $2338-4794$

e-ISSN: 2579-7476

Vol.8. No. 1 Januari-April 2020

\title{
KINERJA PORTOFOLIO DENGAN METODE SHARP, JENSEN DAN TREYNOR PADA SAHAM INDUSTRI TEKSTIL DI BURSA EFEK INDONESIA
}

\author{
Akhmad Sodikin*) \\ *) Dosen Program Studi Magister Manajemen FE UNKRIS \\ Alamat: Kampus UNKRIS, Jatiwaringin Jakarta Timur \\ email: ihin_2007@yahoo.co.id
}

\begin{abstract}
This study aims to determine portfolio performance using the methods of Sharp, Jensen and Treynor. The companies involved in this study were 18 companies in the industry group of textile which were listed on the Indonesia Stock Exchange in 2016. Data were taken monthly for 12 months. The data is then analyzed to determine the elements needed in the analysis namely market profits, standard deviation of profits (total risk), beta (systematic risk) and risk free profits (risk free). Based on data analysis, it is known that portfolio performance is calculated using 3 methods, namely Sharp, Treynor and Jensen methods in the textile industry stock which includes 18 companies which are mostly negative. However, if it is classified according to non-negative values, then the performance according to the Treynor and Jensen methods can be used as a reference because all of the items that are compared have positive values. According to the Treynor Index shares that can be used as a reference for entry in investments are CNTB, CNTX, ERTX, HDTX and ARGO shares. Meanwhile, according to Jensen's index of shares that can be included in the investment are SSTM, STAR, MYTX and POLY.
\end{abstract}

Keywords: Portfolio performance, sharp index, treynor index and jensen index

\section{PENDAHULUAN}

Teori portofolio dimulai dengan asumsi bahwa tingkat pengembalian atas efek dimasa depan dapat diestimasi dan kemudian menentukan risiko dengan variasi distribusi pengembalian. Dengan asumsi tertentu, teori portofolio menghasilkan hubungan linear antara risiko dan pengembalian.

Teori portofolio adalah pendekatan investasi yang diprakarsai oleh Makowitz (1927) seorang ekonom lulusan Universitas Chicago yang telah memperoleh Nobel Prize di bidang ekonomi pada tahun 1990. Teori portofolio berkaitan dengan estimasi investor tehadap ekspektasi risiko dan return, yang diukur secara statistik untuk membuat portofolio investasinya. Markowitz menjabarkan cara mengkombinasikan aset ke dalam diversifikasi portofolio yang efisien.

Untuk menentukan kinerja portofolio diperlukan penilaian kinerja portofolio menurut Sharp, Jensen dan Treynor. Jack L. Treynor adalah orang pertama yang menyediakan pengukur komposit kinerja portofolio yang juga memperhitungkan risiko. Tujuan Treynor adalah menemukan ukuran kinerja yang dapat diaplikasikan kepada seluruh investor, tidak mempedulikan preferensi risiko personal. Ia menyarankan bahwa ada komponen risiko, yakni risiko yang dihasilkan dari fluktuasi di pasar dan risiko yang muncul dari fluktuasi sekuritas individual.

Treynor memperkenalkan konsep garis pasar sekuritas, yang mendefinisikan hubungan antara hasil 
portofolio dan tingkat hasil pasar, dimana kemiringan garis mengukur volatilitas relatif antara portofolio dan pasar (yang diwakili dengan beta).

Rasio Sharpe hampir identik dengan pengukuran Treynor, kecuali bahwa pengukuran risiko adalah standar deviasi portofolio, bukan mempertimbangkan risiko sistematik, yang ditampilkan oleh beta. Seperti pengukuran kinerja yang didiskusikan sebelumnya, pengukuran Jensen juga didasarkan pada CAPM . Dinamakan sesuai pembuatnya, Jensen, pengukuran Jensen memperhitungkan kelebihan hasil (excess return) yang diperoleh sebuah portofolio melebihi hasil yang diharapkan.

\section{LANDASAN TEORI}

\section{Portofolio}

Teori portofolio (portfolio theory) menyatakan bahwa risiko dan pengembalian keduanya harus dipertimbangkan dengan asumsi tersedia kerangka formal untuk mengukur keduanya dalam pembentukkan portofolio. Dalam bentuk dasarnya, teori portofolio dimulai dengan asumsi bahwa tingkat pengembalian atas efek dimasa depan dapat diestimasi dan kemudian menentukan risiko dengan variasi distribusi pengembalian. Dengan asumsi tertentu, teori portofolio menghasilkan hubungan linear antara risiko dan pengembalian.

Dalam portofolio ini, risiko dapat dikurangi dengan menambah jumlah jenis aset ke dalam portofolio dan tingkat expected return dapat naik jika investasinya terdapat perbedaan pergerakan harga dari aset-aset yang dikombinasi tersebut ("Markowitz") Pada prakteknya para pemodal pada sekuritas sering melakukan diversifikasi dalam investasinya dengan mengkombinasikan berbagai sekuritas, dengan kata lain mereka membentuk portofolio.
Menurut Husnan (2003), portofolio berarti sekumpulan investasi. Tahap ini menyangkut identifikasi sekuritassekuritas mana yang akan dipilih dan berapa proporsi dana yang akan ditanamkan pada masing-masing sekuritas tersebut. Pemilihan banyak sekuritas (pemodal melakukan diversifikasi) dimaksudkan untuk mengurangi risiko yang ditanggung. Pemilihan sekuritas ini dipengaruhi antara lain oleh preferensi risiko, pola kebutuhan kas, status pajak, dan sebagainya.

Evaluasi Kinerja Portofolio Dalam tahap evaluasi, pemodal melakukan penilaian terhadap kinerja (performance) portofolio, baik dalam aspek tingkat keuntungan yang diperoleh maupun risiko yang ditanggung. Menurut Husnan (2003), tidaklah benar jika portofolio yang memberikan keuntungan yang lebih tinggi mesti lebih baik dari portofolio lainnya.

Menurut John (2005), Kerja besar dikerahkan untuk pembentukan portofolio. Teori portofolio (portfolio theory) menyatakan bahwa risiko dan pengembalian keduanya harus dipertimbangkan dengan asumsi tersedia kerangka formal untuk mengukur keduanya dalam pembentukkan portofolio.

Dalam bentuk dasarnya, teori portofolio dimulai dengan asumsi bahwa tingkat pengembalian atas efek dimasa depan dapat diestimasi dan kemudian menentukan risiko dengan variasi distribusi pengembalian. Dengan asumsi tertentu, teori portofolio menghasilkan hubungan linear antara risiko dan pengembalian. Teori portofolio mengasumsikan bahwa investor yang rasional menolak untuk meningkatkan risiko tanpa disertai peningkatan pengembalian yang diharapkan. Hubungan antara risiko yang diterima dan pengembalian yang diharapkan merupakan dasar bagi keputusan 
pinjaman dan investasi modern. Makin besar risiko atas investasi atau pinjaman, makin besar tingkat pengembalian yang diinginkan untuk menutup risiko tersebut.

\section{Penelitian terdahulu}

Wijaya (2014) melakukan penelitian mengenai kinerja portofolio. Data yang dipergunakan pada penelitian ini adalah laporan keuangan tahunan perusahaan pada sektor manufaktur periode 2014. Analisis data yang digunakan dalam melakukan penelitian ini adalah metode analisis data kuantitatif, yaitu analisis data dengan menggunakan data berupa angka-angka. Data tersebut diperoleh dari nilai harga saham bulanan perusahaan sampel terpilih. Alat analisis data yang digunakan dalam penelitian ini adalah Metode Indeks' Tunggal. Dalam hasil penelitian ini diternukan bahwa untuk membentuk portofolio dengan lima kine rja terbaik pornfolio perusahaan yang sebaiknya dipilih oleh investor adalah PT Gudang Garam, Tbk (GGRM), PT Delta Djakarta, Tbk (DLTA), PT HM Sampoema, Tbk (HMSP), PT Multi Bintang Indonesia, Tbk (MLBI) dan PT Unilever Indonesia, TBK (UNVR).

Eko (2008) menjelaskan kombinasi saham-saham yang membentuk portofolio optimal ditentukan dengan melihat peringkat masing-masing saham berdasarkan nilai ERB/Excess Return to Beta (model indeks tunggal) dan ERS/Excess Return to Deviation Standard (model korelasi konstan). Portofolio optimal yang dibentuk dengan menggunakan model indeks tunggal maupun model korelasi konstan mengindikasikan bahwa investor harus mengalokasikan dana terbesarnya pada Saham TLKM, sedangkan portofolio optimal yang dibentuk dengan menggunakan model korelasi konstan memiliki kinerja yang lebih baik jika dibandingkan dengan portofolio optimal yang dibentuk dengan menggunakan model indeks tunggal. Membentuk portofolio optimal, investor harus mempertimbangkan beberapa faktor lain diluar faktor harga saham, Indeks LQ-45, dan tingkat SukuBunga Bank Indonesia (SBI). Faktor lain yang perlu dipertimbangkan dalam pembentukan portofolio optimal adalah faktor makro ekonomi dan analisis fundamental emiten.

Dua faktor ini perlu dipertimbangkan karena pada dasarnya semakin baik kinerja emiten yang bersangkutan, akan semakin baik pula kinerja saham dari emiten yang bersangkutan. Selain itu, dengan memperhatikan dua hal tersebut diharapkan investor dapat lebih tepat dalam membentuk portofolio yang optimal. Penelitian ini mengasumsikan bahwa tingkat pengembalian antara dua saham atau lebih akan berkorelasi (bergerak bersama) dan mempunyai reaksi yang sama terhadap satu faktor atau indeks tunggal yang dimasukkan dalam model, yaitu Indeks LQ-45. Namun, dalam kenyataannya tingkat pengembalian saham (expected return) dan tingkat risiko yang digambarkan dengan standar deviasi dan kovarians saham secara aktual tidak hanya sensitif terdapat lebih dari satu faktor yang mempengaruhinya. Oleh karena itu, dalam penelitian selanjutnya perlu juga dimasukkan faktor lain selain Indeks LQ45 (IHSG), yaitu tingkat pengembalian atas investasi (ROI), tingkat pemgembalian atas sekuritas (ROE), tingkat bunga deposito bank pemerintah, tingkat inflasi, laba per saham (EPS), dan faktor lainnya.

\section{METODE PENELITIAN}

Metode Pengumpulan Data 
Pada penelitian ini menggunakan data sekunder berupa data keuangan yang bersumber dari neraca, laporan laba rugi dan laporan perubahan modal. Data yang diambil adalah selama 10 periode sesuai dengan ketersediaan data pada perusahaan.

\section{Metode Analisis Data}

\section{Pengukuran Treynor}

Koefisien beta secara sederhana mengukur volatilitas saham, portofolio atau pasar itu sendiri. Semakin besar kemiringan garis, semakin baik tradeoff risiko-hasil. Pengukuran Treynor, juga dikenal sebagai imbalan kepada rasio volatilitas, dapat dengan mudah didefinisikan sebagai: Hasil Portofolio - Tingkat Bebas-Risiko) / Beta Pembilang mengidentifikasi premium risiko dan denominator berkaitan dengan risiko portofolio.

Semakin tinggi ukuran Treynor, semakin baik portofolio. Mungkin Anda pernah mengevaluasi manajer portofolio (atau portofolio) hanya berdasarkan kinerja, dan secara tidak sengaja mengidentifikasi Manajer C memberikan hasil yang terbaik. Kendati demikian, ketika mempertimbangkan risiko yang diambil masing-masing manajer untuk memperoleh hasil mereka masingmasing, Manajer B menunjukkan hasil yang lebih baik. Dalam kasus ini, ketiga manajer itu berkinerja lebih baik daripada pasar agregat. Karena pengukuran ini hanya memperhitungkan risiko sistematik, maka diasumsikan bahwa investor sudah mempunyai portofolio yang terdiversifikasi dengan baik dan, oleh karena itu, risiko tidak sistematik (atau risio yang dapat didiversifikasi) tidaklah dipertimbangkan. Akibatnya, pengukuran kinerja ini sebaiknya hanya digunakan oleh investor yang memiliki portofolio yang terdiversifikasi.
Kinerja portofolio menurut Tryenor maka kinerja porto folio diukur dengan rumus sebagai berikut: $\mathrm{Tp}=\mathrm{Rp}-\mathrm{Rf} / \mathrm{bp}$ dalam hal ini

$\mathrm{Tp}=$ indeks kinerja Treynor

$\mathrm{Rp}=$ return portofolio

$\mathrm{Bp}=$ risiko pasar

\section{Rasio Sharpe}

Pengukuran yang diperkenalkan oleh Bill Sharpe ini, terkait erat dengan pekerjaannya pada model penetapan harga aset modal (capital asset pricing model/CAPM) dan diperjelas dengan menggunakan risiko total untuk membandingkan portofolio terhadap garis pasar modal. Rasio Sharpe didefinisikan sebagai berikut: (Hasil Portofolio - Tingkat Bebas Risiko) / Standar Deviasi.

Sebaliknya, portofolio dengan hasil risiko disesuaikan (risk-adjusted return) paling superior, atau dalam kasus ini dana yang dikelola oleh manajer X. Tidak seperti pengukuran Treynor, rasio Sharpe mengevaluasi portofolio manajer berdasarkan tingkat hasil (rate of return) dan diversifikasi (seperti mempertimbangkan risiko portofolio total sebagaimana diukur dengan standar devisiasi pada denominatornya). Oleh karena itu, rasio Sharpe lebih sesuai untuk portofolio yang terdiversifikasi dengan baik, karena lebih akurat memperhitungkan risiko portofolio.

Sharpe mengemukakan kinerja porto folio dapat ditulis dengan menggunakan formula sebagai berikut : $\mathrm{S} p=\mathrm{R} p-\mathrm{R} f / \mathrm{d} p$ dalam hal ini

$\mathrm{S} p=$ indeks sharpe

$\mathrm{R} p=$ return portofolio

$\mathrm{R} f=$ risk free (keuntungan bebas risiko)

$\mathrm{d} p=$ total resiko (Manurung, 2000). Jika portofolio sama dengan portofolio pasar maka total risiko sama dengan risiko sistematis.

\section{Pengukuran Jensen}


Pengukuran ini juga dikenal sebagai alpha. Rasio Jensen mengukur seberapa banyak tingkat hasil portofolio ditabalkan pada kemampuan manajer untuk mendapatkan hasil di atas ratarata. Sebuah portofolio dengan kelebihan hasil yang positif akan mempunyai alpha yang positif, sedangkan portofolio yang secara konsisten memberikan kelebihan hasil yang negatif akan mempunyai alpha yang negatif.

Formulanya dapat dijabarkan sebagai berikut: Jensen Alpha = Hasil Portofolio - Hasil Portofolio Acuan. Dimana : Acuan Hasil ( CAPM ) = Tingkat Hasil Bebas Risiko + Beta (Hasil Pasar - Tingkat Hasil Bebas Risiko)

Pengukuran Jensen membutuhkan penggunaan tingkat hasil bebas risiko yang berbeda untuk masing-masing interval waktu yang dipertimbangkan. Oleh karena itu, katakanlah Anda ingin mengevaluasi kinerja fund manager untuk periode lima tahun menggunakan interval tahunan; Anda juga harus menelaah hasil tahunan reksa dana minus tingkat bebas risiko yang sama. Sebaliknya, Treynor dan rasio Sharpe menelaah rata-rata hasil untuk suatu periode total yang dipertimbangkan untuk semua variabel di dalam formula (portofolio, pasar dan aset bebas risiko). Kendati demikian, seperti pengukuran Treynor, variabel alpha pada Jensen memperhitungkan premium risiko dengan terminologi beta (sistematik, risiko tidak terdiversifikasi) dan oleh karena itu mengasumsikan bahwa portofolio sudah terdiversifikasi dengan baik. Oleh karena itu, rasio ini akan memberikan hasil terbaik jika diaplikasikan dengan portofolio terdiversifikasi, seperti reksa dana.

Ukuran kinerja portofolio sebaiknya menjadi aspek kunci proses keputusan investasi. Perangkat tersebut memberikan informasi yang diperlukan bagi investor untuk menilai seberapa efektif dana mereka telah diinvestasikan (atau dapat diinvestasikan). Perlu diingat, hasil portofolio hanyalah satu bagian cerita. Tanpa mengevaluasi hasil risiko yang disesuaikan, seorang investor kemungkinan besar tak akan melihat seluruh gambaran investasi, yang mungkin secara tidak sengaja menyebabkan keputusan investasi yang suram.

Pada Indeks Jensen maka perhitungan kinerja portofo folio dihitung dengan rumus sebagai berikut: $\mathrm{ap}=\mathrm{Rp}-(\mathrm{Rf}+\mathrm{bp}(\mathrm{Rm}-\mathrm{Rf})$

dalam hal ini

ap=indeks Jansen

$\mathrm{Rp}=$ return portofolio

$\mathrm{Rf}=$ return investasi bebas risiko $\mathrm{bp}=$ beta pasar

\section{PEMBAHASAN}

Jika portofolio sama dengan portofolio pasar maka total risiko sama dengan risiko sistematis. Data yang dimpun dari 18 saham perusahaan kelompok industri tekstil dapat dilihat pada tabel berikut.

Tabel 1. Nilai Kinerja Portofolio Sharp

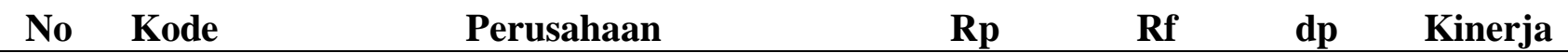




\begin{tabular}{rllrrrr}
\hline 1 & ADMG & PT. Polychem Indonesia Tbk & 0,00134 & 0,045 & 0,21049 & $-0,2074$ \\
2 & ARGO & Argo Pantes Tbk & 0,00134 & 0,045 & 0,0126 & $-3,4648$ \\
3 & CNTB & Century Textile Industry Tbk (seri B) & 0,00134 & 0,045 & 5,76441 & $-0,0076$ \\
4 & CNTX & Century Textile Industry Tbk (PS) & 0,00134 & 0,045 & 5,40871 & $-0,0081$ \\
5 & ERTX & Eratex Djaya Tbk & 0,00134 & 0,045 & 2,09895 & $-0,0208$ \\
6 & ESTI & Ever Shine Textile Industry & 0,00134 & 0,045 & 0,32926 & $-0,1326$ \\
7 & HDTX & Panasia Indo Resources & 0,00134 & 0,045 & 0,22556 & $-0,1936$ \\
8 & INDR & Indo Rama Synthetics & 0,00134 & 0,045 & 0,159 & $-0,2746$ \\
9 & MYTX & Apac Citra Centertex & 0,00134 & 0,045 & 0,17691 & $-0,2468$ \\
10 & PBRX & Pan Brother Tbk & 0,00134 & 0,045 & 0,09997 & $-0,4367$ \\
11 & POLY & Asia Pasific Fibers & 0,00134 & 0,045 & 0,09384 & $-0,4653$ \\
12 & RICY & Ricky Putra Globalindo & 0,00134 & 0,045 & 0,08437 & $-0,5175$ \\
13 & SRIL & Sri Rejeki Isman Tbk & 0,00134 & 0,045 & 0,18499 & $-0,236$ \\
14 & SSTM & Sunson Textile Manufacturer Tbk & 0,00134 & 0,045 & 0,34952 & $-0,1249$ \\
15 & STAR & Star Petrochem Tbk & 0,00134 & 0,045 & 0,14642 & $-0,2982$ \\
16 & TFCO & Tifico Fiber Indonesia Tbk & 0,00134 & 0,045 & 0,20838 & $-0,2095$ \\
17 & TRIS & Trisula International Tbk & 0,00134 & 0,045 & 0,08714 & $-0,501$ \\
18 & UNIT & Nusantara Inti Corpora & 0,00134 & 0,045 & 0,19729 & $-0,2213$ \\
\hline
\end{tabular}

Sumber: data dianalisis

Berdasarkan pada data tersebut dapat dilihat besar indeks sharp. Kinerja saham perusahaan kelompok industri tekstil semuanya bernilai negatif pada tahun 2016. Dalam hal ini kinerja saham tersebut tidak menunjukkan kinerja yang baik karena nilai keuntungan pasar negatif. Nilai kinerja pasar yang tidak baik disebabkan karena IHSG pada periode berikutnya menurun.

Jika disusun kinerja terbaik berdasarkan nilai minus terkecil maka dapat dilihat pada tabel berikut.

Tabel 2. Kinerja 5 Besar Saham menurut Indeks Sharp Kelompok Tekstil di BEI tahun 2016

\begin{tabular}{ccc}
\hline Ranking & Kode & Nilai Kinerja \\
\hline 1 & CNTX & $-0,00807$ \\
2 & CNTB & $-0,00757$ \\
3 & ERTX & $-0,0208$ \\
4 & SSTM & $-0,12491$ \\
5 & ESTI & $-0,1326$ \\
\hline
\end{tabular}

Sumber: data dianalisis

Dalam hal bagi investor dapat mempetimbangkan ke lima saham tersebut untuk investasi di Bursa Efek Indonesia.

Kinerja Portofolio Menurut Treynor

Kinerja portofolio menurut Tryenor diukur dengan rumus sebagai berikut: $\mathrm{Tp}=\mathrm{Rp}-\mathrm{Rf} / \mathrm{bp}$ dalam hal ini

$\mathrm{Tp}=$ indeks kinerja Treynor

$\mathrm{Rp}=$ return portofolio

$\mathrm{bp}=$ risiko pasar

Berdasarkan pada analisis data maka hasil kinerja portofolio dapat dilihat pada tabel berikut 
Tabel 3. Kinerja Portofolio Menurut Treynor

\begin{tabular}{cllrlrr}
\hline No & Kode & \multicolumn{1}{c}{ Perusahaan } & Rp & Rf & \multicolumn{1}{c}{ Bp } & \multicolumn{1}{c}{ Kinerja } \\
\hline 1 & ADMG & PT. Polychem Indonesia Tbk & 0,00134 & 0,045 & 1,77816 & $-0,0246$ \\
2 & ARGO & Argo Pantes Tbk & 0,00134 & 0,045 & $-0,1581$ & 0,27609 \\
3 & CNTB & Century Textile Industry Tbk (seri B) & 0,00134 & 0,045 & $-85,98$ & 0,00051 \\
4 & CNTX & Century Textile Industry Tbk (PS) & 0,00134 & 0,045 & $-80,869$ & 0,00054 \\
5 & ERTX & Eratex Djaya Tbk & 0,00134 & 0,045 & $-32,009$ & 0,00136 \\
6 & ESTI & Ever Shine Textile Industry & 0,00134 & 0,045 & $-4,9815$ & 0,00876 \\
7 & HDTX & Panasia Indo Resources & 0,00134 & 0,045 & $-1,7554$ & 0,02487 \\
8 & INDR & Indo Rama Synthetics & 0,00134 & 0,045 & 0,13818 & $-0,316$ \\
9 & MYTX & Apac Citra Centertex & 0,00134 & 0,045 & 1,58825 & $-0,0275$ \\
10 & PBRX & Pan Brother Tbk & 0,00134 & 0,045 & 0,33415 & $-0,1307$ \\
11 & POLY & Asia Pasific Fibers & 0,00134 & 0,045 & 1,28828 & $-0,0339$ \\
12 & RICY & Ricky Putra Globalindo & 0,00134 & 0,045 & 0,07779 & $-0,5612$ \\
13 & SRIL & Sri Rejeki Isman Tbk & 0,00134 & 0,045 & 1,18064 & $-0,037$ \\
14 & SSTM & Sunson Textile Manufacturer Tbk & 0,00134 & 0,045 & 3,95496 & $-0,011$ \\
15 & STAR & Star Petrochem Tbk & 0,00134 & 0,045 & 1,62751 & $-0,0268$ \\
16 & TFCO & Tifico Fiber Indonesia Tbk & 0,00134 & 0,045 & $-0,8888$ & 0,04912 \\
17 & TRIS & Trisula International Tbk & 0,00134 & 0,045 & 0,792 & $-0,0551$ \\
18 & UNIT & Nusantara Inti Corpora & 0,00134 & 0,045 & 1,63806 & $-0,0267$ \\
\hline
\end{tabular}

Sumber: data dianalisis

Berdasarkan pada data tersebut dapat dilihat besar indeks Treynor namun nilai indeks tersebut sebagian besar negatif karena nilai $\mathrm{Rp}$ atau keuntungan pasar negatif. Jika akan diinvestasikan maka perlu ditentukan ranking terbaik dari kinerja tersebut seperti dapat dilihat pada tabel berikut.

Tabel 4. Kinerja 5 Besar Saham menurut Indeks Treynor Kelompok Tekstil di BEI tahun 2016

\begin{tabular}{ccc}
\hline Ranking & Kode & Kinerja \\
\hline 1 & CNTB & 0,00051 \\
2 & CNTX & 0,00054 \\
3 & ERTX & 0,00136 \\
4 & HDTX & 002487 \\
5 & ARGO & 0,27609 \\
\hline
\end{tabular}

Sumber: data dianalisis

Kinerja Portofolio Menurut Jensen

Pada Indeks Jensen maka perhitungan kinerja portofo folio dihitung dengan rumus sebagai berikut: $\mathrm{ap}=\mathrm{Rp}-(\mathrm{Rf}+\mathrm{bp}(\mathrm{Rm}-\mathrm{Rf})$

dalam hal ini

ap=indeks Jansen
$\mathrm{Rp}=$ return portofolio

$\mathrm{Rf}=$ return investasi bebas risiko $\mathrm{bp}=$ beta pasar

Berdasarkan pada analisis data maka hasil kinerja portofolio dapat dilihat pada tabel berikut 
Tabel 5. Kinerja Portofolio Menurut Jensen

\begin{tabular}{cllrrrr}
\hline No & Kode & \multicolumn{1}{c}{ Perusahaan } & Rp & Rf & \multicolumn{1}{c}{ Bp } & \multicolumn{1}{c}{ Kinerja } \\
\hline 1 & ADMG & PT. Polychem Indonesia Tbk & 0,00134 & 0,045 & 1,77816 & 0,03397 \\
2 & ARGO & Argo Pantes Tbk & 0,00134 & 0,045 & $-0,1581$ & $-0,0506$ \\
3 & CNTB & Century Textile Industry Tbk (seri B) & 0,00134 & 0,045 & $-85,98$ & $-3,7976$ \\
4 & CNTX & Century Textile Industry Tbk (PS) & 0,00134 & 0,045 & $-80,869$ & $-3,5744$ \\
5 & ERTX & Eratex Djaya Tbk & 0,00134 & 0,045 & $-32,009$ & $-1,4412$ \\
6 & ESTI & Ever Shine Textile Industry & 0,00134 & 0,045 & $-4,9815$ & $-0,2612$ \\
7 & HDTX & Panasia Indo Resources & 0,00134 & 0,045 & $-1,7554$ & $-0,1203$ \\
8 & INDR & Indo Rama Synthetics & 0,00134 & 0,045 & 0,13818 & $-0,0376$ \\
9 & MYTX & Apac Citra Centertex & 0,00134 & 0,045 & 1,58825 & 0,02568 \\
10 & PBRX & Pan Brother Tbk & 0,00134 & 0,045 & 0,33415 & $-0,0291$ \\
11 & POLY & Asia Pasific Fibers & 0,00134 & 0,045 & 1,28828 & 0,01259 \\
12 & RICY & Ricky Putra Globalindo & 0,00134 & 0,045 & 0,07779 & $-0,0403$ \\
13 & SRIL & Sri Rejeki Isman Tbk & 0,00134 & 0,045 & 1,18064 & 0,00789 \\
14 & SSTM & Sunson Textile Manufacturer Tbk & 0,00134 & 0,045 & 3,95496 & 0,12901 \\
15 & STAR & Star Petrochem Tbk & 0,00134 & 0,045 & 1,62751 & 0,0274 \\
16 & TFCO & Tifico Fiber Indonesia Tbk & 0,00134 & 0,045 & $-0,8888$ & $-0,0825$ \\
17 & TRIS & Trisula International Tbk & 0,00134 & 0,045 & 0,792 & $-0,0091$ \\
18 & UNIT & Nusantara Inti Corpora & 0,00134 & 0,045 & 1,63806 & 0,02786 \\
\hline
\end{tabular}

Sumber: data dianalisis

Berdasarkan pada data tersebut dapat dilihat besar indeks Jensen namun nilai indeks tersebut sebagian besar negatif karena nilai $\mathrm{Rp}$ atau keuntungan pasar negatif. Jika akan diinvestasikan maka perlu ditentukan ranking terbaik dari kinerja tersebut seperti dapat dilihat pada tabel berikut.

Tabel 6. Kinerja 5 Besar Saham menurut Indeks Jensen Kelompok Tekstil di BEI tahun 2016

\begin{tabular}{ccc}
\hline Ranking & Kode & Kinerja \\
\hline 1 & SSTM & 0,12901 \\
2 & ADMG & 0,03397 \\
3 & STAR & 0,00274 \\
4 & MYTX & 0,02568 \\
5 & POLY & 0,01259 \\
\hline
\end{tabular}

Sumber: data dianalisis

\section{KESIMPULAN DAN SARAN}

\section{Kesimpulan}


Kinerja portofolio yang dihitung dengan mengunakan 3 metode yaitu metode Sharp, Treynor dan Jensen pada saham industri tekstil yang meliputi 18 perusahaan memiliki nilai yang sebagian besar negatif. Namun jika diklasifikan menurut nilai yang tidak negatif maka kinerja menurut metode Treynor dan Jensen yang dapat dijadikan acuan karena seluruh sahan yagn dibandingkan memiliki nilai positif.

Menurut Indeks Treynor saham yang dapat dijadikan referensi untuk masuk pada investasi adalah saham CNTB, CNTX, ERTX, HDTX dan ARGO. Sedangkan menurut indeks Jensen saham yang dapat dimasukan kedalam investasi tersebut adalah SSTM, STAR, MYTX dan POLY.

\section{Saran}

Investor dapat mempertimbangkan saham yang memiliki indeks Treynor dan Indeks Jensen yang positif untuk membentuk portofolio investasi pada Bursa Efek Indonesia. Namun Investor perlu untuk mempertimbangkan kelompok industri lain agar kombinasi lebih baik. Oleh karena itu perlu penelitian lain yang menggunakan kelompok industri berbeda yang dapat digunakan untuk referensi portofolio tersebut.

\section{DAFTAR PUSTAKA}

Boedie, Z., Kane, A., and Alan, M.J.,2000, Investment, Second Edition, Von Hoffman Press Inc, USA
Brealey, Myers, Marcus, 2006, DasarDasar Manajemen Keuangan Perusahaan, Erlangga, Jakarta

Eko, U. 2008. Analisis dan Penilaian Kinerja Portofolio Optimal SahamSaham LQ-45. Bisnis \& Birokrasi, Jurnal Ilmu Administrasi dan Organisasi, Sept-Des 2008, hlm. 178-187 ISSN 0854-3844

Riyanto, Bambang, 2008. Dasar-Dasar Pembelajaran

Perusahaan, BPFE, Yogyakarta.

Sawir, Agnes, 2009. Analisa Kinerja Keuangan dan Perencanaan Keuangan Perusahaan, PT. Gramedia Pustaka Utama, Jakarta.

Setiawan dan Kusrini. 2010. Ekonometrika. Penerbit Andi. Yogyakarta

Sharp. 2000. Financial Management. Irwin. Newjersey

Van Horne, J dan Wachowicz, Jr. 2012. Fundamental of Financial Management. Pearson Education

Yuliani . 2013. Pengaruh Perputaran Piutang Terhadap Profitabilitas Pada Perusahaan PT. Uniler Indonesia Tbk. Tahun 2005-2012

Weston, Fred J dan Brigham, F. Eugene. 2012. Manajemen Keuangan. Erlangga

Wijaya, H. 2014. Implementasi Analisis Kinerja Portofolio Saham Dengan Metode Sharpe, Tremvor Dan Jensen (Studi Kasus Saham Perusahaan Manufaktur 2014). Jurnal Bisms, Manajemen \& Ekonomi Fakultas Bisnis Dan Manajemen Universitas Widyatama 